\title{
Ki-67 is expressed in multiplying forms of Schistosoma mansoni, but not in snail host tissues
}

\author{
Tânia Maria Correia Silva, Samaly dos Santos Souza, Tais Fontoura de Almeida, \\ Zilton A Andrade ${ }^{+}$
}

\author{
Laboratório de Patologia Experimental, Centro de Pesquisas Gonçalo Moniz-Fiocruz, Rua Valdemar Falcão 121, 40295 -001 \\ Salvador, BA, Brasil
}

Ki-67 is a protein expressed in the nucleus of several species during cell-division, being absent during the GO resting phase of the cellular cycle. During attempts to disclose mitosis in the so-called "amebocyte-producing organ" in Biomphalaria glabrata infected with Schistosoma mansoni, the parasite multiplying forms appeared strongly marked for Ki-67, while the snail tissues were completely negative. These data are worth registering to complement general data on Ki-67, and to help future studies on the relationship of the parasite and of its intermediate host.

Key words: Ki-67 - Schistosoma mansoni - Biomphalaria glabrata

There are two different views concerning the origin of the hemocytes, the cells of defense found both circulating in the hemolymph and infiltrating the interstitial tissues of the snail Biomphalaria glabrata, the main intermediate host of Schistosoma mansoni in Brazil. One view postulates the presence of a specific organ, the amebocyte producing organ or APO, from where all the defense cells would take origin (Sminia et al. 1974, Lie et al. 1976, Sullivan 1990). One main argument in favor of this theory derives from the observation of an increased number of cells in mitosis within the APO when the snails become infected with $S$. mansoni (Sullivan 1990). The other view, which happens to be the primitive one, considers that the hemocytes originate from cells lining the vascular spaces and wandering within the interstitial connective tissue, anywhere throughout in the snail body (Haughton 1934, Pan 1958). Recently, a series of evidences were presented in favor of this latter view (Souza \& Andrade 2006). It was exactly during the course of that mentioned comparative studies that the histochemical method for Ki-67, a mitosis marker, was used in an attempt to test how prominent was mitosis in the APO during the course of experimental S. mansoni infection of $B$. glabrata. No evidence of mitosis was detected in the APO or anywhere else throughout the snail tissues. However, the multiplying parasite structures were strongly marked. Since this unexpected finding seems important to be incorporate into the general body of Ki-67 data, as well as to data on the biology of the parasite, and of its intermediate host, it is herein further presented and discussed.

\footnotetext{
${ }^{+}$Corresponding author: zilton@ @ cpqgm.fiocruz.br Received 5 January 2007 Accepted 24 April 2007
}

Sections of paraffin-embedded formalin-fixed snail tissues, from both $S$. mansoni infected and non-infected B. glabrata, were submitted to treatment with the monoclonal anti-Ki67 (mouse $\mathrm{IgG}$, clone MIB-1 DAKO, Carpinteria, US).

Antigen retrieval was accomplished through heat treatment in citrate buffer at $\mathrm{pH}$ 6.0. After washing in Tween 20 $0.1 \%$ PBS, the others steps were done with LSAB (DAKO) kit sections were incubated with the primary antibodies overnight, at $4^{\circ} \mathrm{C}$ in a humidified chamber. Primary antibodies were diluted in DAKO's antibody diluent Af 2\% BSA in PBS (pH 7.4). After washing in PBS, sections were incubated in $10 \%$ skimmed milk during 20 min for blocking non-specific ligations. Blockade of the endogenous peroxidase was done with $3 \% \mathrm{H}_{2} \mathrm{O}_{2}$ for $10 \mathrm{~min}$ at room temperature. The color was developed with 3,3-diaminobenzidine tetrahydrochloride (DAB) (DAKO). Sections were counterstained with Harris hematoxilyn for $2 \mathrm{~min}$, dehydrated and mounted with Permount. Control sections in which primary antibody was either omitted or replaced by normal mouse serum, were used.

Ki-67 appeared strongly and exclusively expressed in the multiplying forms of $S$. mansoni, sporocysts and developing cercariae (Fig. 1, B, C, D). It was more marked in sporocysts than in the developing cercariae. The cells lining the cavities containing the sporocyst, probably the most primitive on the germinal line, appeared strongly positive (Fig. 1D). The snail tissues showed no labelling at all, including the ovo-testis where numerous mitoses are usually present.

$\mathrm{Ki}-67$ is a phosphoprotein present in the nucleus during the G1, S, G2, M phases of cell division in different tissues of different species. Since it is absent during the GO resting phase of the cellular cycle, it results in an excellent marker of cell division (Scholen \& Gerdes 2000). The monoclonal antibody anti-Ki-67 is a mouse IgG1 kappa against a recombinant human peptide fragment containing 1002 pairs of basis from the Ki-67 cDNA. Such antibody tags to the nucleolar protein present exclusively within the nucleus undergoing division and at the chromosome surface (Gerdes et al. 1991). 

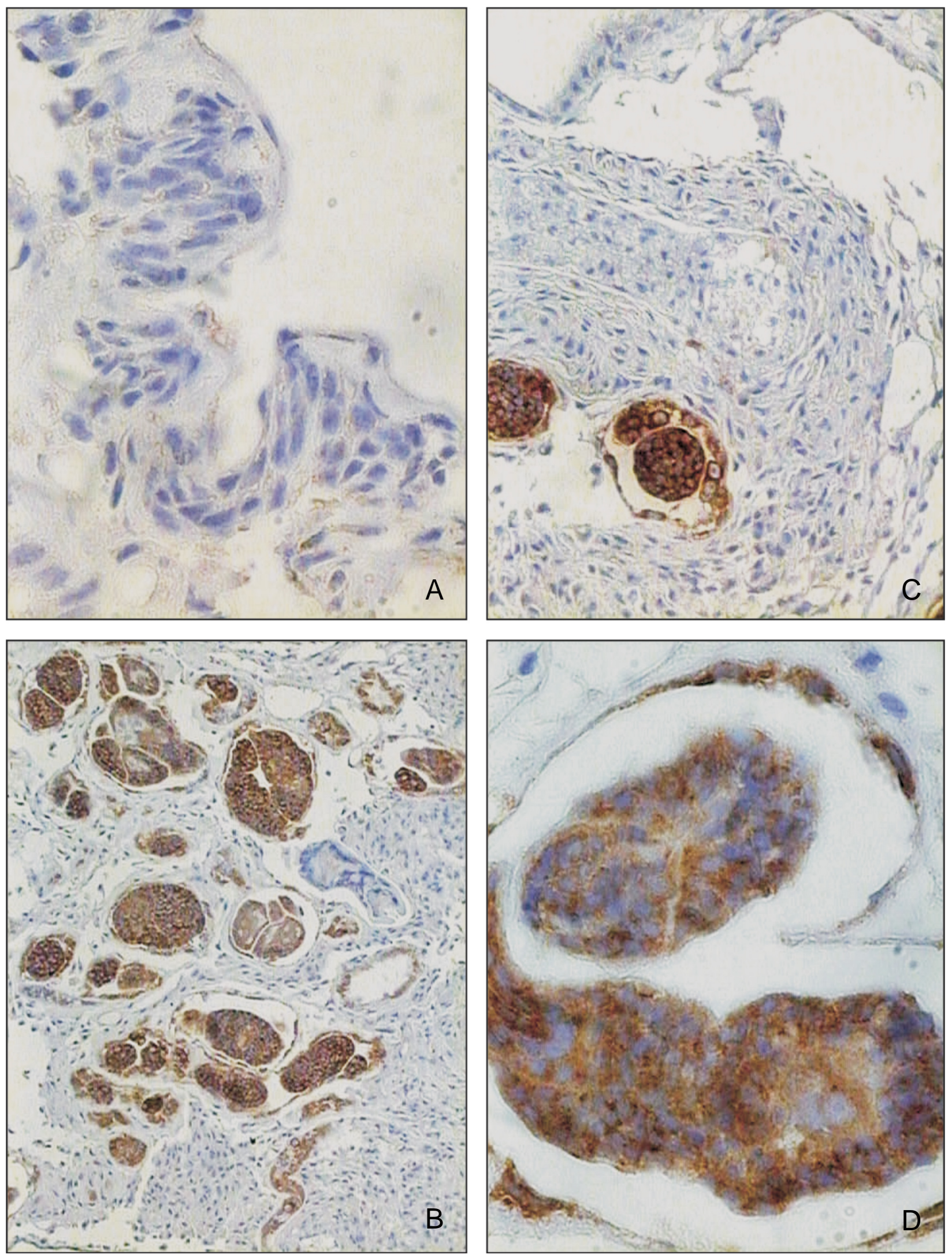

Fig. 1A: the cells forming the amebocyte producing-organ appear unstained for Ki-67; B and C: Ki-67 appears strongly expressed within the multiplying forms of Schistosoma mansoni, including the cells lining the inner sporocyte cavity (D). Monoclonal Ki-67 immuno-histochemical technique. $\mathrm{X} 200$ for A, B, C; X400 for D. 
The primary protein structure was deducted from cDNA and does not show homology with any other known polypeptide (Scholen \& Gerdes 2000). The NCBI (Nacional Center for Biotechnology Information) data basis identifies possible $\mathrm{Ki}-67$ homologues genes in Homo sapiens, as well as in other mammals and nonmammals, among them, Pan troglodytes, Mus musculus, Rattus novergicus, Gallus gallus, Anopheles gambiae, Arabidopsis thaliana, Oryza sativa, Bos taurus, Danio rerio, Gasterosteus aculeatus, Helianthus annus, Hordeum vulgare, Lactuca sativa, Lycopersicon esculentum, Macaca mullata, Oncorhynchus mykiss, Oryzias latipes, Ovis aries, Pimephales promelas, Salmo salar, Solanum tuberosum, Saguinus bicolor, Sus scrofa, Triticum aestium, Vitis vinifera, Xenopus laevis, Xenopus tropicalis. Although the S. mansoni genoma is mentioned on the NCBI, no reference has been found related to the presence of Ki-67 homologue gene in that parasite. However a search through GeneDB, a data-basis maintained by the Welcome Trust Sanger Institute, responsible for the $S$. mansoni genome project, indicated a relationship between the human Ki-67 mensager RNA (RNAm) and three $S$. mansoni proteins, hitherto not described.

Like the human Ki-67 protein, these hypothetical proteins contain the forkhead-associated (FHA) domain (Hofmann \& Bucher 1995). Proteins with FHA domain are related to phosphorylation-dependent protein-protein interactions in a wide range of cellular functions, including RNA processing, cell cycle arrest and nuclear repair ( $\mathrm{Li}$ et al 2000). Moreover, a possible ligand to Ki-67 was also identified on $S$. mansoni through a search on GeneDB. The putative protein Smp_078520 (MKI67 FHA domain-interacting nucleolar phosphoprotein) corresponds to NIFK (nucleolar protein interacting with the FHA domain of pKI-67), a human protein described as a ligand to the FHA domain (Takagi et al. 2001). These data indicates the variety of proteins that can emerge from the studies of the $S$. mansoni genome.

The use of Ki-67 histochemical staining may be of help during studies related to $S$. mansoni and $B$. glabrata relationship, but has been of no avail to clarify the role of APO as a hemocyte production site, as postulated by some (Sminia 1974, Lie et al.1976, Sullivan 1990), because this marker is not expressed in snail tissues.

\section{REFERENCES}

Gerdes J, Li L, Schlueter C, Duchrow M, Wohlenberg C, Gerlach C, Starmer I, Kloth S, Brandt E, Flad D-Hans 1991. Immunobiochemical and molecular biologic characterization of the cell proliferation-associated nuclear antigen that is defined by monoclonal antibody Ki-67. Am J Pathol 138: 867-873.

Haughton L 1934. Amebocytes and allied cells in Invertebrata. J Roy Microscop Soc 54: 246-462.

Hofmann K, Bucher P 1995. The FHA domain: a putative nuclear signalling domain found in protein kinases and transcription factors. Trends Bioch Sci 20: 347-349.

Li J, Lee G-I, Van Doren SR, Walker JC 2000. The FHA domain mediates phosphoprotein interactions. J Cell Sci 113: 4143-4149.

Lie KJ, Heyneman D, Jeong KH 1976. Studies on resistance in snails. 4. Induction of ventricular capsules and changes in amebocytes producing organ during sensitization of Biomphalaria glabrata snails. J Parasitol 62: 286-291.

Pan Chia-Tung 1958. The general histology and topographic microanatomy of Australorbis glabrata. Bull Mus Comp Zool 119: 237-299.

Sholzen T, Gerdes J 2000. The ki67 protein: from the known and the unknown (review). J Cell Physiol 182: 311-322.

Sminia T, Borghart-Reinders E, Linde AW 1974. Van der encapsulation of foreign materials experimentally introduced intro the freshwater snail Lymnaea stagnalis. Cell Tissue Res 153: 307-326.

Souza SS, Andrade ZA 2006. On the origin of the Biomphalaria glabrata hemocytes. Mem Inst Oswaldo Cruz 101(Suppl. 1): 213-218.

Sullivan JT 1990. Long-term survival of heterotopic allografts of the amebocyte-producing organ in Biomphalaria glabrata (Mollusca: Pulmonata). Trans Am Microsc Soc 109: 52-60.

Takagi M, Sueishi M, Saiwaki T, Kametaka A, Yoneda Y 2001. A novel nucleolar protein, NIFK, interacts with the Forkhead Associated Domain of K1-67 antigen in mitosis. J Biol Chem 276: 25386-25391. 
